\title{
Estádios de desenvolvimento de mudas de umbuzeiros propagadas por enxertia
}

\author{
Developmental stages of umbu fruit seedlings propagated by grafting
}

\author{
Ronaldo Viana dos Reis ${ }^{I^{*}}$ Nelson Fonseca ${ }^{\text {II }}$ Carlos Alberto da Silva Ledo ${ }^{\text {II }}$ \\ Leandro Simões Azeredo Gonçalves ${ }^{\mathrm{I}}$ Fábio Luiz Partelli'II \\ Marcelo Geraldo de Morais Silva ${ }^{\mathrm{I}}$ Elaine Alves Santos ${ }^{\mathrm{IV}}$
}

\section{RESUMO}

\begin{abstract}
O reconhecido potencial econômico das Spondias (como o umbuzeiro) e o crescente interesse dos mercados internacionais em razão da demanda de frutos com sabores exóticos utilizados no preparo de sucos, doces e sorvetes têm despertado o interesse de pesquisadores e produtores por essa fruteira. Os objetivos do trabalho foram avaliar o desenvolvimento de mudas de umbuzeiro e indicar a melhor idade da muda e do garfo para a realização da enxertia. A semeadura foi realizada em canteiros de madeira de $1,5 \mathrm{~m}$ de largurax $10,0 m$ de comprimento $\times 0,15 \mathrm{~m}$ de altura, contendo areia lavada, sendo as sementes colocadas juntas e alinhadas em fileiras espaçadas de 5,0 cm uma da outra. Avaliou-se a altura da muda a partir do colo da planta, do número de folhas, do diâmetro do caule a 5, 10 e $15 \mathrm{~cm}$ do colo, da matéria fresca e seca da parte aérea e das raízes no dia do transplante e após 60, 120, 180 e 240 dias após o transplantio. Avaliou-se também a sobrevivência das mudas com 180 dias após o transplantio, por meio da enxertia, pelo método de garfagem em fenda cheia ao topo com material propagativo (garfos) de umbuzeiros de várias procedências e idades. $O$ delineamento utilizado foi o inteiramente casualizado, $e$ as repetições foram compostas por seis plantas por parcela. Conclui-se que, a partir de seis meses depois da repicagem, as mudas do umbuzeiro podem ser enxertadas pelo método de garfagem em fenda cheia ao topo. Houve uma sobrevivência de $80 \%$ das mudas enxertadas, estando estas prontas para o plantio em campo depois de dois meses após a enxertia. $O$ índice de pegamento diminuiu de forma gradual ao serem usados garfos oriundos de plantas com idade acima de seis anos.
\end{abstract}

Palavras-chave: Spondias tuberosa, umbu, propagação vegetativa.

\section{ABSTRACT}

The economic importance of Spondias umbuzeiro has been increased in international market due to its exotic flavor and the ability to be used in juices, ice creams and other food preparation. For this reason, the knowledge of many aspects of this species is has been investigated by many researchers and also attracted the farmers interest. The aim of this research was to evaluate the development of umbu seedlings and to indicate the best stage of the seedling and also the more appropriate stage of the fork for grafting. Seeds were sown in wood beds with $1.5 \mathrm{~m}$ wide $10.0 \mathrm{~m}$ long $0.15 \mathrm{~m}$ high, washed sand, and placed together and aligned in rows spaced $5.0 \mathrm{~cm}$ apart. The following characteristics were evaluated: seedling size, leaves number, stem diameter at 5, 10 and $15 \mathrm{~cm}$ from the soil, canopy and root fresh weight in the transplant date and also after 60, 120, 180 and 240 days after transplanting. The grafting technique studied consisted in a top bench grafting with seedlings from different origins and development stages. The efficiency of grafting technique was evaluated after 180 days after transplanting by observing the surviving plants. The experiments were carried out in a completely casualized design and the replicates made up of six plants per plot. It was concluded that from six months after transplanting the umbuzeiro seedlings can be grafted by using top cleft grafting. The efficiency of grafting technique reached $80 \%$ of all genotypes tested. The same results were observed considering plants after two months when the plants were already planting in a definitive place. The survival index decreased gradually when forks from plants older than six years were used.

Key words: Spondias tuberosa, umbu fruit, vegetative propagation.

IUniversidade Estadual do Norte Fluminense Darcy Ribeiro (UENF), 28013-602, Campos dos Goytacazes, RJ, Brasil. E-mail: ronasviana@yahoo.com.br.*Autor para correspondência.

IEmbrapa Mandioca e Fruticultura Tropical, Cruz das Almas, BA, Brasil.

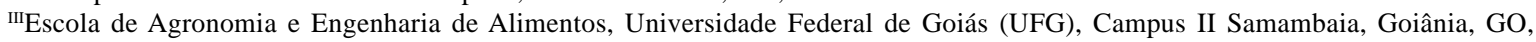
Brasil.

${ }^{\text {IV} U n i v e r s i d a d e ~ C a t o ́ l i c a ~ d o ~ S a l v a d o r ~(U C S A L), ~ S a l v a d o r, ~ B A, ~ B r a s i l . ~}$ 


\section{INTRODUÇÃO}

O umbuzeiro (Spondias tuberosa Arruda Cam.) é uma Anacardiácea, do gênero Spondias, formado por, aproximadamente, 17 espécies, das quais sete encontram-se distribuídas na América Tropical e, aproximadamente, 10 na Ásia Tropical (MILLER \& SCHAAL, 2005). É uma árvore xerófita endêmica do Semiárido brasileiro (PRADO \& GIBBS, 1993), não existindo relatos de sua ocorrência em outras regiões do mundo. Essa Anacardiácea, pela sua adaptação ao Semiárido e aproveitamento secular, tem desempenhado importante papel agrossocioeconômico, sendo o extrativismo de seu fruto bastante significativo na composição da renda familiar em algumas comunidades da região do Nordeste brasileiro. Contudo, o extrativismo desordenado de frutos tem apresentado declínio constante ao longo dos últimos 20 anos (SANTOS et al., 2005).

A propagação do umbuzeiro é realizada quase que exclusivamente por semente. As plantas propagadas por via seminal demandam cerca de 10 anos para apresentarem produção, e a germinação das sementes tarda entre 12 e 90 dias, ocorrendo por volta de 40 dias. Segundo ANDRADE et al. (1989), a germinação do umbuzeiro é rápida, o que se justifica pelos curtos períodos chuvosos das regiões de maior ocorrência da planta.

A principal vantagem das plantas provenientes de sementes é a formação dos xilopódios durante os primeiros 30 dias após a germinação (GONDIM et al., 1991). As plantas provenientes de estacas mostram dificuldades em formar essas estruturas em sua fase inicial de desenvolvimento. Além disso, por ser uma dicotiledônea, as plantas originárias de sementes formam raiz pivotante, estrutura não observada nas plantas provindas de estacas. Assim, as plantas provenientes de sementes podem ser mais resistentes a tombamentos ocasionados por ventos fortes, em comparação às propagadas por estacas.

A produção de mudas em escala comercial tornou-se factível, uma vez que trabalhos de quebra de dormência (CAMPOS, 1986; NASCIMENTO \& SANTOS, 1998) conseguiram reduzir o período de germinação das sementes e uniformizar a emergência das plântulas. Já a recomendação de mudas enxertadas para plantio, em escala agronômica, se deve ao fato de que a sobrevivência dessas plantas vindas de sementes, em campo, pode alcançar $100 \%$, em contraste com plantas oriundas de estaquia, que apresentaram apenas $6 \%$ de sobrevivência em campo (NASCIMENTO et al., 1993).
A propagação vegetativa de plantas mantém as características genéticas da planta matriz, o que garante a homogeneidade do pomar, bem como características desejáveis da planta selecionada e ainda apresenta a vantagem da precocidade inicial da produção (HARTMANN et al., 2002). Assim, a enxertia pode ser vantajosa para a cultura do umbu; no entanto, não se conhece a viabilidade desse método de propagação.

A identificação do período ideal do transplante dos porta-enxertos de umbuzeiro, da idade de realizar a enxertia e dos garfos apropriados para estas é importante para um maior fornecimento de mudas de qualidade. Dessa forma, o presente trabalho teve como objetivos avaliar o desenvolvimento de mudas de umbuzeiro e indicar a idade das mudas e dos garfos apropriados para a realização da enxertia.

\section{MATERIAL E MÉTODOS}

O experimento foi conduzido sob telado de sombrite de 50\% de luminosidade, na Embrapa Mandioca e Fruticultura Tropical, em de Cruz das Almas, Bahia (BA).

As sementes foram embebidas em água por 24 horas. A semeadura foi realizada em 03/04/2006, em canteiros de madeira de $1,5 \mathrm{~m}$ de largurax10,0m de comprimentox $0,15 \mathrm{~m}$ de altura, contendo areia lavada, sendo as sementes colocadas juntas e alinhadas em fileiras espaçadas de 5,0 cm uma da outra. Após a germinação das sementes, foi realizado o transplante das plântulas de $5,0 \mathrm{~cm}$ de altura para sacos de polietileno de $30 \mathrm{~cm} \times 25 \mathrm{~cm} \times 0,20 \mathrm{~mm}$, contendo substrato composto por terra, esterco de gado curtido na proporção 3:1 e 2kg de superfosfato simples por metro cúbico da mistura.

As avaliações do crescimento das mudas foram efetuadas no dia do transplantio da muda para o saco de polietileno com substrato e após 60, 120, 180 e 240 dias. Os materiais propagativos utilizados foram obtidos de várias localidades, com diferentes idades: a) os materiais de Cruz das Almas-BA foram obtidos de plantas com dois anos; b) os materiais da Embrapa Semiárido, em Petrolina-PE, foram obtidos de plantas com quatro anos; c) os materiais da Empresa de Pesquisa Agropecuária de Minas Gerais (EPAMIG), em Janaúba-MG, foram obtidos de plantas com cerca de seis anos de idade; d) os materiais da comunidade de Boa Fé, em São Domingos-BA, foram obtidos de plantas com cerca de 40 anos (Deusdária e Maçã) e 60 anos (Umbu Grande); e e) os materiais da Escola Agrícola, em Monte Santo-BA, foram obtidos de plantas com cerca de 80 anos. 
Durante o experimento, foram efetuadas a limpeza dos sacos plásticos, a irrigação das plantas, a aplicação de fertilizante foliar e três podas apicais (aos 80, 140 e 200 dias após o transplantio) para proporcionar o aumento do diâmetro do caule.

Foram avaliados a altura da planta a partir do colo da planta, o número de folhas, o diâmetro do caule a 5, 10 e $15 \mathrm{~cm}$ do colo e as matérias fresca e seca da parte aérea e das raízes. Foi efetuada a limpeza das raízes do substrato em água corrente. A parte aérea e as raízes foram separadas e colocadas em sacos de papel e em estufa a $60^{\circ} \mathrm{C}$, permanecendo assim até apresentarem massa constante.

Avaliou-se o pegamento das mudas com 180 dias após o transplantio, por meio da enxertia pelo método de garfagem em fenda cheia ao topo com material propagativo (garfos e ponteiros) de Umbuzeiros de várias procedências: 10 acessos de Janaúba-MG cedidos pela EPAMIG, um cedido pela Escola Agrícola de Monte Santo-BA, três da Comunidade Boa Fé em São Domingos-BA e nove da Embrapa Semiárido Petrolina-BA. Além disso, foram testados dois acessos de Umbucajazeiras presentes na Embrapa Mandioca e Fruticultura Tropical em Cruz das Almas-BA
Todos os materiais coletados foram acondicionados em folhas de jornal umidecido, colocados em sacos plásticos e transportados ao local onde foi realizada a enxertia. As observações do pegamento das mudas enxertadas foram iniciadas a partir da segunda semana e se estenderam por dois meses, quando se obteve o percentual total de pegamento.

O delineamento utilizado foi o inteiramente casualizado, com cinco tratamentos $(0,60,120,180$ e 240 dias de avaliação) e seis repetições. Realizou-se análise de variância a 1\% de significância, pelo teste F. Para as médias dos tratamentos, foram ajustadas equações de regressão polinomial.

\section{RESULTADOS E DISCUSSÃO}

A percentagem de pegamento de cada acesso foi analisada de acordo com o pegamento das mudas em relação ao número de plantas enxertadas e avaliadas (Tabela 1). Observou-se que houve efeito significativo para a fonte de variação épocas em todas as variáveis estudadas, indicando diferenças entre as

Tabela 1 - Mudas enxertadas e percentuais de pegamento de umbuzeiros da EPAMIG (Janaúba - MG), Escola Agrícola (Monte Santo-BA), Comunidade Boa Fé (São Domingos-BA), Embrapa Semiárido (Petrolina-PE) e de Umbucajazeiras (Cruz das Almas - BA) em porta-enxerto. Cruz das Almas, BA, 2009.

\begin{tabular}{|c|c|c|c|c|}
\hline ACESSOS & Data de Enxertia & Mudas Enxertadas & Enxertos Pegados & \% Pegamento \\
\hline EPAMIG 01 (Janaúba) & $04 / 10 / 06$ & 46 & 41 & 89,13 \\
\hline EPAMIG 02 (Janaúba) & 02/10/06 & 66 & 62 & 93,93 \\
\hline EPAMIG 03 (Janaúba) & 03/10/06 & 124 & 107 & 86,29 \\
\hline EPAMIG 04 (Janaúba) & 03/10/06 & 55 & 54 & 98,18 \\
\hline EPAMIG 06 (Janaúba) & 02/10/06 & 107 & 99 & 92,52 \\
\hline EPAMIG 07 (Janaúba) & 04/10/06 & 81 & 78 & 96,29 \\
\hline EPAMIG 08 (Janaúba) & $02 / 10 / 06$ & 76 & 71 & 93,42 \\
\hline EPAMIG 09 (Janaúba) & 03/10/06 & 89 & 85 & 95,50 \\
\hline EPAMIG 10 (Janaúba) & 04/10/06 & 68 & 59 & 86,76 \\
\hline EPAMIG 13 (Janaúba) & $04 / 10 / 06$ & 60 & 57 & 95,00 \\
\hline Escola Agrícola (Monte Santo) & $13 / 10 / 06$ & 122 & 14 & 11,47 \\
\hline Umb. Deusdária (São Domingos) & 01/11/06 & 96 & 68 & 70,83 \\
\hline Umbuzeiro Maçã (São Domingos) & $14 / 12 / 06$ & 88 & 64 & 72,72 \\
\hline Umbuzeiro Grande (S.Domingos) & $18 / 12 / 06$ & 56 & 18 & 32,14 \\
\hline Umbuzeiro de Cacho (Petrolina) & $16 / 12 / 06$ & 10 & 08 & 80,00 \\
\hline 44 - Anagé/BA (Petrolina) & $15 / 12 / 06$ & 189 & 143 & 75,66 \\
\hline 45 - L.Brumado/BA (Petrolina) & $14 / 12 / 06$ & 256 & 237 & 92,57 \\
\hline 47 - Guanambí/BA (Petrolina) & $18 / 12 / 06$ & 290 & 246 & 84,82 \\
\hline 48 - Irecê/BA (Petrolina) & $15 / 12 / 06$ & 218 & 191 & 87,61 \\
\hline 50 - S.M.Vitória/BA (Petrolina) & $15 / 12 / 06$ & 273 & 218 & 79,85 \\
\hline 61 - Januária/MG (Petrolina) & $18 / 12 / 06$ & 370 & 276 & 74,59 \\
\hline 68 - Lontra/MG (Petrolina) & $14 / 12 / 06$ & 282 & 211 & 74,82 \\
\hline 75 - Paramirim/BA (Petrolina) & $14 / 12 / 06$ & 164 & 150 & 91,46 \\
\hline Umbucaj. Ouro (Cruz das Almas) & $22 / 11 / 06$ & 116 & 95 & 81,89 \\
\hline Umbucaj. Princesa (Cruz das Almas) & $23 / 11 / 06$ & 146 & 130 & 89,04 \\
\hline TOTAL GERAL & & 3448 & 2782 & 77,94 \\
\hline
\end{tabular}


épocas de avaliação das mudas. Os coeficientes de variação variaram de 8,97 a $35,75 \%$ para os caracteres diâmetro a $15 \mathrm{~cm}$ e matéria seca da raiz, respectivamente.

Ocorreu comportamento linear crescente dos efeitos da época de avaliação, tanto para altura, quanto para número de folhas (Figura 1A). O incremento máximo das duas características foi obtido na última data de avaliação, contendo valores estimados de 43,27cm de altura e 20,13 folhas.

Verificou-se um comportamento quadrático dos efeitos da época de avaliação das mudas de umbuzeiro para todos os diâmetros avaliados (Figura 1B). Observou-se a diminuição do diâmetro do colo ao aumentar a altura de medição, evidenciando um crescimento cônico do caule. Os maiores diâmetros foram obtidos quando as mudas foram avaliadas aos 240 dias. Notou-se que o incremento do diâmetro entre 180 e 240 dias foi inferior aos demais períodos amostrados.

De uma forma geral, houve um crescimento significativo para todas as características avaliadas do experimento com o decorrer dos dias avaliados. A

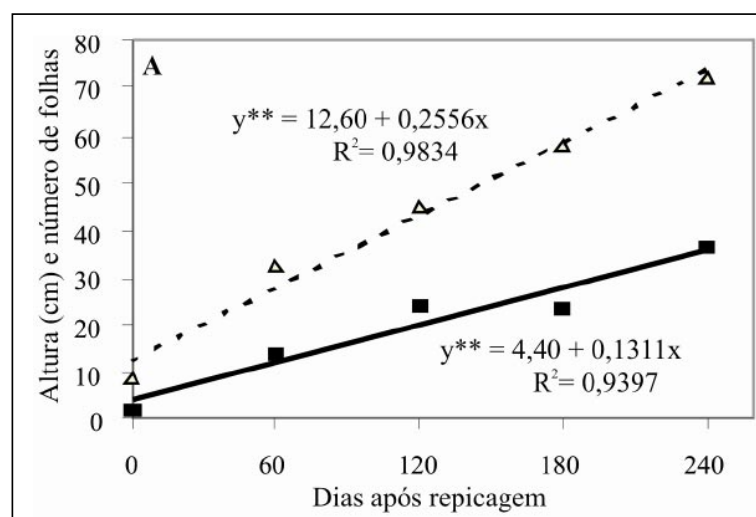

$\Delta$ Altura

- Número de folhas
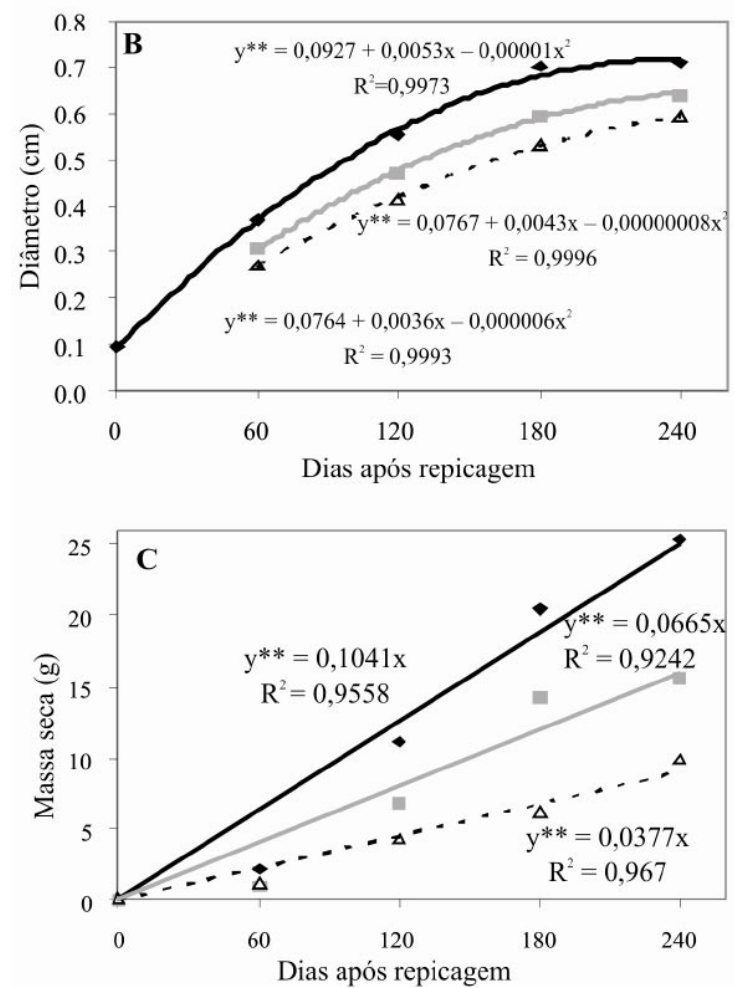

Figura 1- Altura da planta a partir do colo e número de folhas de mudas de umbuzeiros até 240 dias após enxertia (A), Diâmetro do caule a 5, 10 e 15cm do colo de mudas de umbuzeiros até 240 dias após enxertia (B) e Matéria seca da parte aérea, raízes e total de mudas de umbuzeiros até 240 dias após enxertia (C). Cruz das Almas, BA 2009. 
característica marcante para determinar se a muda está em condições de ser enxertada é o diâmetro do caule, na altura da enxertia. Portanto, este já apresentava menor engrossamento a partir de 180 dias (Figura 1B), e nas condições estudadas, a partir de seis meses após a repicagem, a muda de umbuzeiro estava pronta para ser enxertada, tanto a $10 \mathrm{~cm}$, como a $15 \mathrm{~cm}$ do colo da planta, pelo método de enxertia por garfagem em fenda cheia ao topo

Aos seis meses, o diâmetro do caule apresentava em torno de $0,59 \mathrm{~cm}$ e $0,53 \mathrm{~cm}$ de diâmetro a $10 \mathrm{~cm}$ e $15 \mathrm{~cm}$ do colo da planta, respectivamente. ESPÍNDOLA et al. (2004) obtiveram bons níveis de pegamento em mudas de umbuzeiro a $0,4-0,6 \mathrm{~cm}$ de diâmetro. Aos 240 dias após a repicagem, o diâmetro do caule apresentava $0,68 \mathrm{~cm}$ e $0,61 \mathrm{~cm}$ de diâmetro nas respectivas alturas do colo da planta. Esse fato sugere que as plantas já podem ser enxertadas aos 180 dias, pois apresentam condições para realização desse procedimento. Além disso, notou-se que o diâmetro principalmente a $5 \mathrm{~cm}$ do colo já não apresentava ganhos nessa medida com o passar dos dias de desenvolvimento, e o aumento do diâmetro a 10 e $15 \mathrm{~cm}$ do colo da planta entre 180 e 240 dias foi muito pequeno.

Verificou-se também um comportamento linear crescente da matéria seca da planta, da parte aérea e das raízes das mudas de umbuzeiro nas diversas avaliações (Figura 1C). O incremento máximo obtido nas duas características foi obtido na ultima avaliação aos 240 dias. As outras características avaliadas aos 180 dias após a repicagem da planta apresentaram $60 \mathrm{~cm}$ de altura, 28 folhas, 18,74g de matéria seca da planta, 11,97g de matéria seca da parte aérea e 6,77g de matéria seca das raízes.

Observou-se que o método de enxertia por garfagem em fenda cheia ao topo é viável para produção de mudas selecionadas na cultura do umbuzeiro (Tabela 1). Ocorreu excelente pegamento das enxertias (acima de $90 \%$ ) com a maioria dos acessos provenientes de Janaúba-MG e com dois acessos (45-Livramento de Brumado, BA e 75-Paramirim, BA) de Petrolina-PE. De uma forma geral, considera-se um bom índice de pegamento o valor em torno de $80 \%$ das enxertias realizadas, uma vez que esses resultados foram superiores aos conseguidos por MENDES (1990). Já os resultados encontrados por PEDROSA et al. (1991) apresentaram-se diferentes, com menor índice de pegamento. ESPÍNDOLA et al. (2004) observaram índice de pegamento acima do encontrado neste trabalho em porta-enxerto de umbuzeiro com oito meses de idade pelo método de enxertia por garfagem, tanto a inglesa simples, como em fenda cheia.

Nesse sentido, todos os acessos provenientes de Janaúba-MG e de Cruz das AlmasBA, incluindo a maioria de Petrolina-PE, atingiram índice satisfatório de pegamento dos enxertos. Isso pode ser atribuído, principalmente, ao bom vigor e à sanidade do material propagativo proveniente de plantas com a idade entre dois e seis anos.

Houve pouca variação no índice de pegamento dos acessos dentro das procedências do material propagativo vindo de Janaúba-MG (11,89\%), de Petrolina-PE (17,98\%) e de Cruz das Almas-BA (7,15\%), e essa variação deve ter ocorrido em função do material genético.

A idade da planta para a coleta dos garfos para a realização das enxertias é de grande importância na cultura do umbuzeiro. Notou-se, neste trabalho, um índice de pegamento superior a $80 \%$ das enxertias com garfos provenientes de plantas de idade menos avançada, com até 20 anos (Figura 2). O índice de pegamento com garfos oriundos de plantas com idade acima de 40 anos diminuiu de forma gradual, atingindo os menores valores em plantas senescentes com mais de 80 anos de idade. Esse fato pode estar relacionado à perda de vigor das plantas mais velhas.

\section{CONCLUSÕES}

A partir de seis meses após a repicagem, as mudas do umbuzeiro avaliadas podem ser enxertadas pelo método de garfagem em fenda cheia ao topo, sendo esse método de enxertia viável para produção de mudas selecionadas na cultura do umbuzeiro.

Houve um pegamento de $80 \%$ das mudas enxertadas, e o índice de pegamento diminuiu de forma gradual ao serem usados garfos oriundos de plantas com a idade acima de 40 anos.

Ciência Rural, v.40, n.4, abr, 2010. 


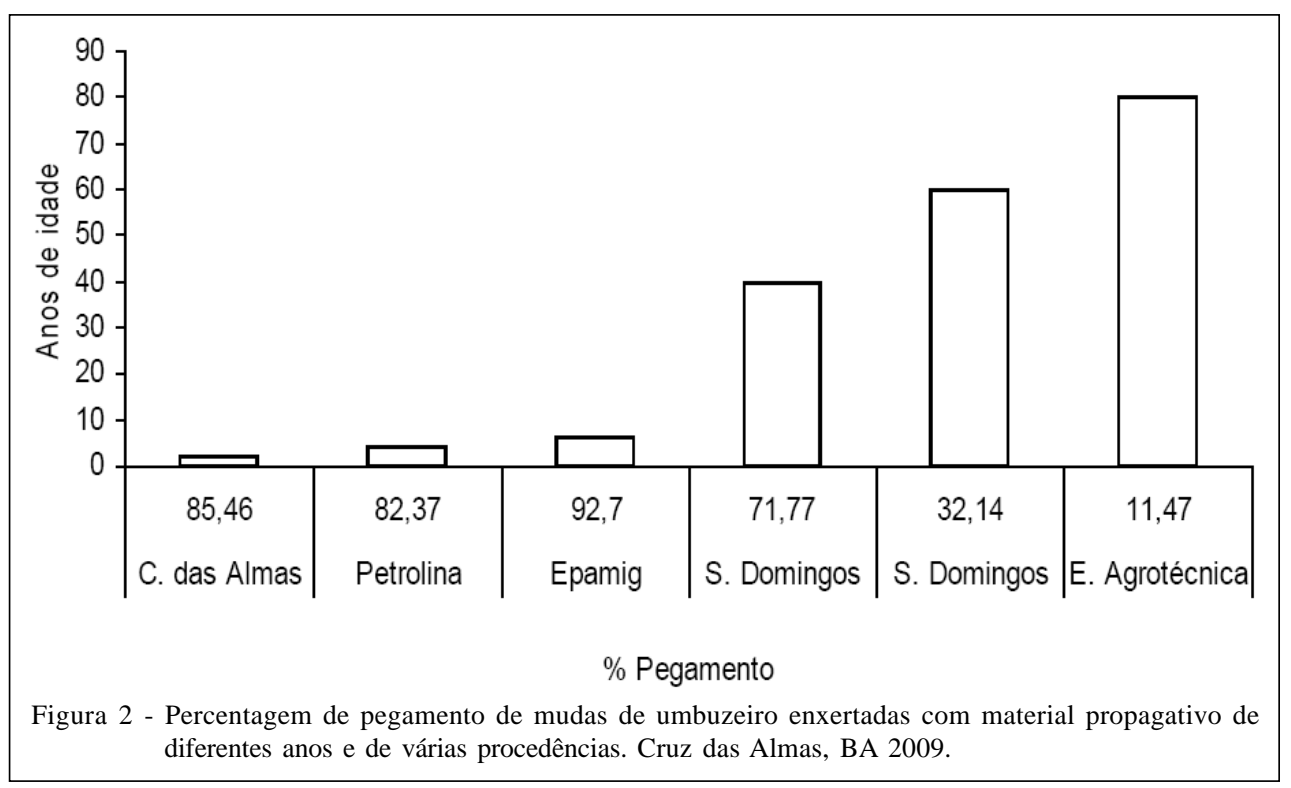

\section{AGRADECIMENTOS}

Os autores agradecem ao Banco do Nordeste do Brasil, pelo apoio financeiro.

\section{REFERÊNCIAS}

ANDRADE, L.A. et al. Imbuzeiro. In: LIMA, D.A. Plantas da Caatinga. Rio de Janeiro: Academia Brasileira de Ciências, 1989. 243p.

CAMPOS, C. de O. Estudos da quebra de dormência da semente do umbuzeiro (Spondias tuberosa, Arr. Camara). 1986. 71f. Dissertação (Mestrado em Agronomia) - Curso de Pós-graduação em Agronomia/Fitotecnia, Universidade Federal do Ceará.

ESPÍNDOLA, A.C.M. et al. Diâmetro do caule e método de enxertia na formação de mudas de umbuzeiro (Spondia tuberosa Arr. Cam). Revista Brasileira Agrociência. Pelotas, v.10, p.371-372, 2004. Disponível em: <http://www.ufpel.edu.br/ faem/agrociencia/v10n3/artigo19.htm>. Acesso em: 21 de out. 2009.

GONDIM, T. M. S. et al. Período de ocorrência e formação de xilopódios em plantas de umbu (Spondias tuberosa Arr. Cam.) propagadas sexuada e assexuadamente. Revista Brasileira de Fruticultura, Cruz das Almas, v.13, p.33-38, 1991.

HARTMANN, H.T. et al. Plant propagation: principles and practices. 7.ed. New Jersey: Prentice Hall, 2002. 880p.
MENDES, B.V. Umbuzeiro (Spondias tuberosa A. Camara.): importante fruteira do semi-árido. Mossoró: ESAM, 1990. 66p. (Série C-554).

MILLER, A.; SCHAAL, B.A. Domestication of a Mesoamerican cultivated fruit tree, Spondias purpurea. PNAS, Washington, v.102, 12801-12806, 2005.

NASCIMENTO, C.E.S. et al. Propagação vegetativa do umbuzeiro. In: CONGRESSO FLORESTAL PANAMERICANO; CONGRESSO FLORESTAL BRASILEIRO, 7., 1993, Curitiba. Anais... São Paulo: SBS/SBEF, 1993. p.454-456.

PEDROSA, A.C. et al. Métodos de enxertia do umbuzeiro (Spondias tuberosa Arr.Cam.) em viveiro. Revista Brasileira de Fruticultura, Cruz das Almas, v.3, n.1, p.59-62, 1991.

PRADO, D. E.; GIBBS, P.E. Patterns of species distributions in the dry seasonal forest South America. Annals of the Missouri Botanical Garden, Missouri, v.80, p.902-927, 1993

SANTOS, C.A.F. et al. Umbuzeiro: pesquisas, potenciais e desafios. In: ROMÃO, R.R.; RAMOS, S.R.R. (Org.). Recursos genéticos vegetais no Estado da Bahia. Feira de Santana: UEFS, 2005. p.69-81.

SANTOS, C.A.F.; NASCIMENTO, C.E.S. Relação entre caracteres quantitativos do umbuzeiro (Spondias tuberosa A. Camara). Pesquisa Agropecuária Brasileira, Brasília, v.33, p.1-8. 1998. Disponível em: <http://www.scielo.br/scieloOrg/ p h p / ref li n ks.php? ref p i d = S 0100 2945200500030002900016 \& p id = S 0100 29452005000300029\&lng=en >. Acesso em: 22 de set. 2009. 